\title{
Attenuation effect of $U V$ on Haemonchus contortus Larvae in Experimentally Infected Goats
}

\author{
S. M. Aboelhadid ${ }^{1}$, M. A. El-Askalany ${ }^{1}$, W. M. Mousa $^{2}$, W. M. Arafa ${ }^{1}$, D. \\ Piedrifita $^{3}$ \\ ${ }^{I}$ Department of Parasitology, Faculty of Veterinary Medicine, Beni-Suef University, Beni-Suef \\ 62511, Egypt, ${ }^{2}$ Department of Parasitology, Faculty of Veterinar Medicine, Cairo University, \\ Cairo, Egypt and ${ }^{3}$ Department of Physiology, Faculty of Veterinary Medicine, Monash University, \\ Australia.
}

This study was conducted to study the UV protective effect against Haemonchus contortus infection in goats. Sixteen male goats were divided into 5 groups, control infected, control uninfected and UV 30minutes; UV 60minutes and UV booster 60minutes exposure. The UV groups were exposed to $U V$ irradiation at wave length $254 \mathrm{~nm}$ for 30 and 60 minutes. The $U V$ booster $60 \mathrm{~min}$ was administrated 2 doses of exposed larvae with an interval of one month. All groups except the control negative one were challenged for 42 days from the beginning. In UV booster $60 \mathrm{~min}$ had reduction in egg count per gram feces and worm burden $(93 \% \& 34 \%$ respectively). These parameters were similar in control infected, UV 30min and UV 60min groups. Increases in levels of antibodies were found in goats of $\mathrm{UV}$ booster $60 \mathrm{~min}$ group the other groups. Finally, 2 doses of UV 60min exposure could protect goats from $H$. contortus.

Gastrointestinal (GIT) nematodes are the chief helminths responsible for diseases. Such diseases lead to production losses, arising from stock mortality, severe weight loss and poor production of milk, meat, wool, and the carcass quality of slaughtered animals. In addition, they cause and infertility problems, especially in the small ruminants (Chiejina, 2001). Haemonchus contortus is one of the dangerous (GIT) nematodes listed among the top 10 conditions hampering of sheep, goats and cattle in tropical countries (Wolstenholme, 1992). Its hazardous effects are characterized by anemia, hemorrhagic gastroenteritis, hypoprotenemia (manifested by edema or bottle jaw), sudden death or chronic emaciation (Urquart et al., 1996).

Attenuation prevented the larvae from maturing into adults, but did not interfere with their infectivity and immunogenicity (Herlich and Tromba, 1980). They also attenuated the infective larvae (L3) of Haemonchus contortus and Chabertia ovina of sheep by means of ultraviolet radiation. UV irradiation was used in a wide range of parasites, Menon \& Bhopale (1985) showed that one oral vaccination of hamsters with 100 infective larvae of Ancylostoma ceylanicum, irradiated by means of UV-tube $(390 \mathrm{~nm})$ at different time intervals, induced the development of resistance. Schistosoma japonicum had the major field for UV-attenuated cercariae and gave high levels of resistance against infection in a number of animal species (Ruppel et al., 1990; Shi et al., 1993; Tian et al., 2010). Besides, Jian et al., (2006) evaluated the protective immunity elicited by ultraviolet-irradiated third-stage infective larvae of Necator americanus (UV$\mathrm{NaL} 3$ ) and Ancylostoma caninum (UV-AcL3) in laboratory mice (a non-permissive model) and hamsters (a permissive model). Allam and Aboel Hadid (2009) exposed the encysted metacercariae of Clinostomum complanatum to UV light $(254 \mathrm{~nm})$ for $60 \mathrm{~min}$. This led to reduction in their development into adult worms in buff-backed herons $(95.7 \%$ reduction in worm burden).

So this work aims to study the effect of UVirradiation on $H$. contortus larvae and evaluation of the protective potency.

\section{Material and methods}

Haemonchus contortus larvae. H. contortus adult worms were obtained from our local abattoir in Beni-Suef city, Egypt. The adult worms were collected from the omasum, and from abomasum of infected abattoir's sheep and were washed several times with phosphate buffer 
saline. Gravid females were incubated in $(0.15$ $\mathrm{M} \mathrm{NaCL}$ ) at $37{ }^{\circ} \mathrm{C}$ for $24-72 \mathrm{hs}$ to induce passage of eggs. Two tablespoonfuls of normal faeces from a sheep were boiled in 100 c.c. of tap water; the mixture was then filtered, and the decoction poured into a Petri dish in a layer of about 1-3 $\mathrm{mm}$. thickness in which the previously collected eggs were added. Then, the Petri dish was kept in the incubator at $26^{\circ} \mathrm{C}$ for 7 to 10 days. The recovered larvae by this method were passed in goats (donor goats), which then used as a source of $H$. contortus L3 by the feacal culture covering all the experiment. The feacal cultures were done according to Eckert (1960), 10 grams of faeces were placed in a plastic jar with saw dust as well as few drops of water to bring the faeces up to the proper consistency, then they were incubated at $28^{\circ} \mathrm{C}$ for 7 to 10 days. The infective third-stage larvae was aspirated by a pipette into marked vials and preserved at $4{ }^{\circ} \mathrm{C}$ until the time of using.

Goats. Six months old 16 male balady goats were obtained from a local producer. Coproscopical analyses were carried out immediately after their arrival to ensure that they are parasite free. The animals were housed indoors, under conditions designed to exclude helminhes infections, and were fed with commercial pelleted food and tap water ad libitum.

UV-irradiation of $H$. contortus larvae. An UV lamp, VL6-LC (ETS Vilber-Louramat, Marne La Vallee, Cedex, France), giving its output at 254 $\mathrm{nm}$, was used in the present study. $25 \mathrm{ml} 0.85 \%$ saline containing (400larvae $/ \mathrm{ml}$ ) was poured into a clear glass dish. It was placed at the center of a closed carton box with dimensions $30 \times 28 \mathrm{~cm}$ above which the UV lamp was adjusted through an opening in the center of the box upper side. The distance between the UV lamp and the suspension surface was $24 \mathrm{~cm}$. To insure stable intensity, the lamp was allowed to warm for $1 \mathrm{~min}$ before being used as a source of radiation. The lamp was returned to full strength within 5 seconds after restoring power. The larvae suspension was exposed to UV radiation for either 30 minutes or 60 minutes. The mobility of larvae after exposure was examined under microscope, according to Allam \& Aboelhadid (2009).
Experimental design. Sixteen goats were divided in a stratified manner to obtain five comparable groups of three animals each, while the third group was different as it consisted of 4 animals. Group 1 represented the unvaccinated control infective group, the second UV 30min was vaccinated with 10,000 irradiated $H$. contortus L3 (ULTRAVILOT attenuated larvae for half hour as a single dose). The third one UV 60min (ULTRAVILOT exposed larvae for one hour) was vaccinated with 10,000 irradiated $H$. contortus L3 as a single dose. The fourth group UV booster 60min (ULTRAVILOT exposed larvae for one hour) was vaccinated with two doses of 10,000 irradiated $H$. contortus L3, with an interval of one month.. Lastly the animals in the fifth group were unvaccinated and even uninfected.

Groups 1, 2, 3 and 4 were challenged with 300 $H$. contortus $\mathrm{L} 3 / \mathrm{kg}$ body weight in 42 days of the experiment. The L3 were used within 3 weeks of recovery from faecal cultures which were administered by stomach tube.

Efficacy of Ultraviolet rays in attenuation of H. contortus L3. The animals of groups 2, 3 and 4 (Ultraviolet vaccinated groups) were examined daily from 16 days post vaccination for the presence of $H$. contotus eggs in the feacal samples. Also one animal of group 3 (UV60min) was slaughtered 30 days after vaccination and its G.I.T (omasum, abomasums and abomasal L.Nds) were examined for the presence of $H$. contortus worms.

\section{Parasitological parameters}

Feacal egg count or Egg per gram feceas (epg). Egg per gram feceas count for all groups was carried daily, from day 16 to day 42 post challenge. The faecal specimens were rectally collected from the individual animals in each group. This took place separately in the morning; and the faecal specimens were examined by using the salt flotation technique. The McMaster technique was used for counting the number of nematode eggs per gram (epg) in faeces (Soulsby, 1982).

Eggs viability. H. contortus eggs of the different groups were examined for their ability to develop and hatch in the feacal culture (Soulsby, 1982).

Worm burden 
The Reduction in Worm burden. The animals were slaughtered at the end of experiment (42d.p.i) to allow recovery of their gastrointestinal tracts (GIT). H. contortus worms were collected from the omasum and abomasums. The worms were counted according to the technique described by Charles \& Baker (1988). Identification and measuring were done, and the worms were separated into male and female groups to calculate the ratio.

Establishment rate. The ability of the challenged $H$. contortus $\mathrm{L} 3$ to reach the phase of the adult worm in the different groups, was calculated by dividing the mean of Worm Burden (W.B) by the challenged dose (ER= worm burden/ challenge dose X 100) according to Gómez-Muñoz et al., (1998).

The relative fertility. It was estimated by dividing the mean of the total eggs/g values obtained by the estimated number of females recorded, and expressed as eggs/g/female (Gómez-Muñoz et al., 1998).

Blood parameters. Blood was collected directly from jugular vein into $5 \mathrm{ml}$ EDTA coated vacutainer tubes at the slaughter time. The blood was immediately transported to the laboratory for further analysis of haematological parameters (PCV and differential leucocytes), Coffin (1995). Immunological status. The blood was collected on zero day, and then it was collected weekly till the end of the experiment. The sera were separated and were stored at $-20 \mathrm{c}$ till used in ELISA.

ELISA. The technique was a modification of the procedure described by Smith et al., (1991). ELISA plates were coated with a $100 \mathrm{ul}$ of the whole worm extract antigen (WWE presented in the laboratory from previous work), which was diluted 1:32 in bicarbonate buffer $(\mathrm{pH}$ 9.6) and incubated at $4^{\circ} \mathrm{C}$ overnight. Plates were washed in wash buffer (Phosphate buffer saline, 0.05\% Tween 20), and blocked for $1 \mathrm{~h}$ at room temperature with a (Phosphate buffer saline, $0.05 \%$ Tween $20,1 \%$ Bovine serum albumin). Serum was diluted at the rate of 1:100 with diluents buffer (Phosphate buffer saline, $0.05 \%$ Tween 20), followed by incubation with a 1:2000 dilution of rabbit anti-goat IgG alkaline phosphatase (Sigma) in (Phosphate buffer saline, $0.05 \%$ Tween 20 ). The colour reaction resulting from the addition of p-nitrophenyl phosphate
(Sigma chemicals), was stopped by adding $50 \mathrm{ul}$ / well of $1 \mathrm{~N} \mathrm{Na} \mathrm{OH}$. The optical densities (O. D) were read at $405 \mathrm{~nm}$ with a micro-ELISA reader system.

Histopathology. Omasum, abomasums and abomasal lymph nodes (L.Ns) were examined macroscopically and microscopically. Abomasal lymph nodes were weighed and their dimensions were measured. Tissue specimens from the omasum, abomasums and abomasal L.Ns of infected goats and control ones were fixed in $10 \%$ formalin solution, and they were embedded in paraffin. Sections 5-7 microns in thickness were prepared and stained with haematoxylin and eosin (H\&E) for microscopically examination according to Carleton (1967).

Statistical analysis. All the data (Worm burden, E.P.G, Eosinophiel count, worm length and L.Nds weight) are statistically analyzed by using SPSS 17, Statistical analyses were performed by the t-Test and One Way ANOVA. Differences were considered significant for $\mathrm{P}<0.05$. All data (eggs per gram of faeces, worm burden PCV) were uniformly distributed according to the Kolmogorov- Smirnov's Normality Test and were expressed as the mean \pm SEM (Standard Error of the Mean).

\section{Results}

Efficacy of Ultraviolet rays in attenuation of H. contortus L3. The fecal examination of each group showed deformed eggs of large size 90$100 \mu \mathrm{m}$ in length and $45-60 \mu \mathrm{m}$ in width, and unclear embryo segmentation (homogenous). In addition, normal eggs appeared only in (UV30 min) after 17 days from vaccination (Fig 1). Both the groups of UV 60min exposed larvae and UV 60min booster didn't show any eggs; after the same period from vaccination. One animal of group 3 (UV 60min) was slaughtered at 30 days post vaccination and its G.I.T (omasum, abomasums) was examined to investigate the presence of any larvae or worms and the results showed no any larvae or worms.

Prepatent period of $\boldsymbol{H}$. contortus and countting egg per gram (epg) feces with the mean in each group. The eggs appeared in fecal examination (The prepatent period) from 18 days post infection in all groups. The mean of egg production in all groups except UV 60min booster group, increased gradually till reaching the peak at $26 \mathrm{dpi}$. Then they remained stable till 
$36 \mathrm{dpi}$, and began to decline gradually (Table 1). In groupUV $60 \mathrm{~min}$ booster, the eggs began to appear at $18 \mathrm{~d}$..p.i and the curve of the mean of eggs production contiued at the same rate with minor variation. Inside the group there is variation in the egg production. The mean of epg for each individuals and the mean of each group was calculated. The mean of daily epg of individuals between 18 and 42 d.p.i was $1867 \pm$ $185,1841 \pm 181$ and $2094 \pm 209$ epg, in the following groups respectively: control infected group,UV 60min and UV 30min. While it was $116 \pm 3$ inUV $60 \mathrm{~min}$ booster group. Finally the egg production was found significatlly different in groupUV $60 \mathrm{~min}$ booster at p 0.05 in comparison with the other groups (Table 1).

Reduction of epg feces. The reduction of epg was $93.7 \%$ in UV $60 \mathrm{~min}$ booster group. In the other groups showed little or no reduction $4 \%$, $1.4 \%$ and $-12 \%$ (negative reduction in UV $30 \mathrm{~min}$ ) (Table 1).

$H$. contortus egg development and hatchability. Unlike the eggs of UV $60 \mathrm{~min}$ booster group, which hatched and produced viable L3, the deformed eggs of UV 30min didn't develop or hatch. But the normal eggs of the later group hatched then completed to infective larvae in both fluid media and feacal culture.

\section{Haemonchus contortus worm}

The worm burden (W.B) of $\boldsymbol{H}$. contortus in each group and the reduction in it. The worm burden was compared between vaccinated groups and the control one, it was significant in groupUV $60 \mathrm{~min}$ booster at $\mathrm{p}>0.05$ with percent of $38.80 \%$. Meanwhile, there was no difference between control infected, UV $30 \mathrm{~min}$ andUV 60min groups (Table 1). Lastly, the reduction percent for these groups showed little or no reduction $0.2 \%, 2$ and $-2.3 \%$ (negative reduction in UV 30min).

Worm sex ratio in the vaccinated groups. The results showed a great variation between the male and female ratio of the same group, when taken individually. But at the groups level the ratio was more or less similar (3:1) (Table 1).

The mean of total epg per worm (relative fertility) and the establishment rate. The relative fertility (total mean of epg and number of mature females) revealed that, 5.4; 5.57; 5.7 and 0.51 ratios were recorded in control infected, UV 30min, UV 60min and UV 60min booster groups respectively. So it was of significant value in UV 60min booster than the other groups (Table, 1). Regarding the establishment rate,UV $60 \mathrm{~min}$ booster showed lower rate in comparison to the other groups.

\section{Blood parameters}

PCV changes. The esults of PCV revealed that UV 60min booster and control negative groups were semilar to each other $(29 \pm 0.5$ and $32 \pm 0.3$ respectvily). PCV of a low epg and low worm burden groups (60min UV booster) were significantly different with PCV of control infected at $p \leq 0.001$ and similar to control negative. PCV of a high epg, and high worm burden groups (control infected,UV 60min and UV 30min) showed significant reduction in $\mathrm{PCV}$, compared with control negative ( $\mathrm{p}$ $\leq 0.001$ ) (Table 2).

Leucocytic differentiation. There was a significant eosinophilia $(\mathrm{p} \leq 0.0001)$ in control infected,UV $60 \mathrm{~min}$ and UV $30 \mathrm{~min}$ groups UV $60 \mathrm{~min}$ booster showed none significant eosinophilia in a comparison with control negative group (Table 2).

Antibodies level detection by ELISA. Increased levels of antibodies were found in goats of the UV 60min booster group two weeks following the booster dose of irradiated larvae. After infection, all the infected groups showed high antibodies level.

Histopathology. In UV 30min group observation of cut larvae within the submucosa of omasum, surrounded with moderate inflammatory reaction. Although there is massive infiltration of eosinophiel within submucosa, the surrounding tissue reaction around larvae was moderate. In UV 60min group, an unchallenged goat was slaughtered 30 days post immunization and its microscopic picture revealed that there were degenerated larvae in the omasal mucosa, associated with mild tissue reaction. The reaction was mild with a weak immune reaction due to the attenuated larva. Marked granulomatus reaction with large number of plasma cells and eosinophiel were detected in omasum submucosa of UV bosster (Fig 2). Marked hyperplasia of lymphoid follicles, medullary cords and proliferation of lymphocytes within the lymphoid follicles of abomasal L.Ns were detected with esinophilic infiltration (Fig 3). 


\section{Discussion}

H. contortus is a serious parasite in terms of morbidity and economy. Because of anthelmintic resistance, efforts have increased in recent years to develop functional vaccines.

Firstly efficacy of Ultraviolet rays in attenuation $H$. contortus L3 was detected. Examination of group UV 60min and UV 60min booster didn't show any eggs post immunization and before challenge. One animal ofUV $60 \mathrm{~min}$ group was slaughtered at 30 day post vaccination and its G.I.T (omasum, abomasums) did not contain any worms. So the term of attenuation which was estimated by Jasmer and Mccuire (1996) was achieved; they noted that, the irradiation of infective larvae inhibited its further development to fourth and adult life cycle stages after infection, thereby providing prolonged antigen stimulation under conditions that largely obviate clinical disease.

Table (1): Mean of eggs per indviduals, mean of worm burden, male to female ratio, establishment rate and relative fertility.

\begin{tabular}{|c|c|c|c|c|}
\hline \multirow{2}{*}{ Parameter } & \multicolumn{4}{|c|}{ Groups } \\
\hline & Control positive & UV 30 m' & UV 60' & UV booster 60 \\
\hline Total Mean of eggs \pm S.E & $1867 \pm 185$ & $2094 \pm 209$ & $1841 \pm 181$ & $116 \pm 3 *$ \\
\hline Mean of worm burden \pm S.E & $1470 \pm 83$ & $1504 \pm 152$ & $1440 \pm 49$ & $900 \pm 40 *$ \\
\hline Establishment rate & 32.6 & 33.4 & 32 & 20 \\
\hline Male to female ratio & 1126: $344(3.2: 1)$ & $1140: 364(3.1: 1)$ & $1119: 321(3.5: 1)$ & $673: 224(3: 1)$ \\
\hline Relative fertility $^{\mathrm{A}}$ & 5.4 & 5.57 & 5.7 & $0.51 *$ \\
\hline
\end{tabular}

A Relative fertility $=$ Mean of total E.P.G / Female NO.

The super script $(*)$ indicates significance within the same row.

Table (2): Differential leucocutic count in the different groups and PCV values.

\begin{tabular}{lllllll}
\hline \multirow{2}{*}{ Group } & \multicolumn{5}{c}{ W.B.Cs } & \multirow{2}{*}{ PCV } \\
\cline { 2 - 6 } & Eosinophiel & Neutrophiel & lymphocyte & Monocyte & Total & \\
\hline Control negative & $6 \pm 0.577$ & $21.3 \pm 1.2$ & 70 & $2.7 \pm 0.61$ & 100 & $32 \pm 0.3^{* *}$ \\
Control infected & $11 \pm 0.5^{* * *}$ & $22 \pm 1.2$ & $64.4 \pm 0.6$ & $2.6 \pm 0.64$ & 100 & $24 \pm 0.5$ \\
UV(60mint) & $20 \pm 1.15^{* * *}$ & $19.9 \pm 1.45$ & $57.4 \pm 2.3$ & $2.7 \pm 0.63$ & 100 & $22.6 \pm 0.8$ \\
UV(30 mint) & $22 \pm 0.5^{* * *}$ & $24.3 \pm 2.3$ & $51 \pm 1$ & $2.7 \pm 0.64$ & 100 & $20 \pm 0.8$ \\
UV booster 60mint & $6.6 \pm 0.3$ & $20 \pm 2.7$ & $70.8 \pm 21$ & $2.6 \pm 0.63$ & 100 & $29 \pm 0.5^{* *}$ \\
\hline
\end{tabular}

$*$ significant at $\mathrm{p} \leq 0.05 * *$ significant at $\mathrm{p} \leq 0.001 * * *$ significant at $\mathrm{p} \leq 0.0001$
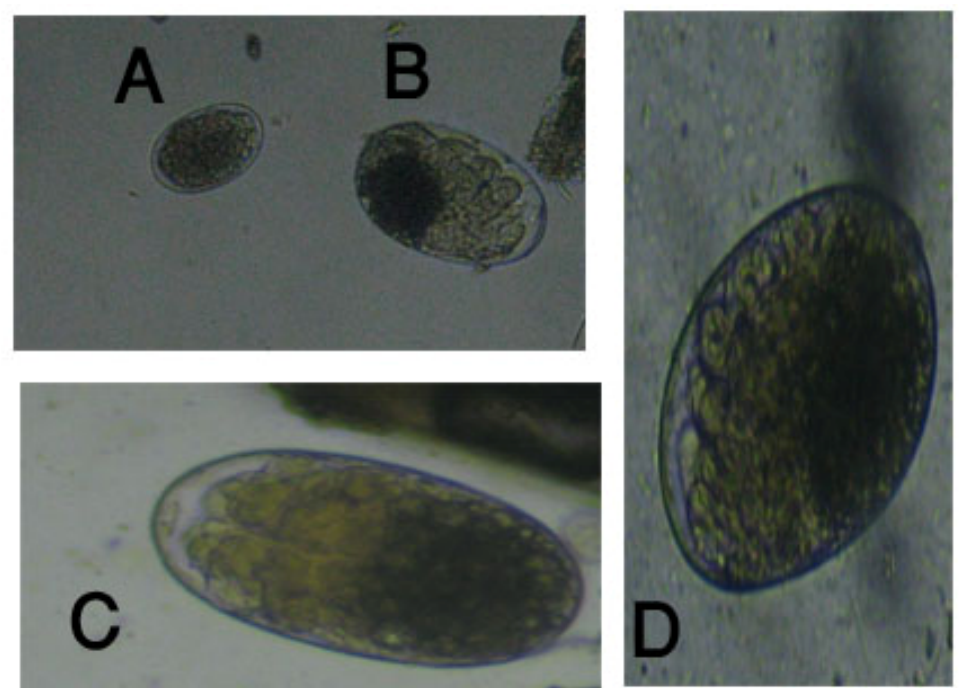

Fig. (1): Deformed eggs (B, C and D) of large size 90-100 $\mu \mathrm{m}$ in length and $45-60 \mu \mathrm{m}$ in width, with unclear embryo segmentation (homogenous) in addition to normal eggs (A) appeared only in (UV30 min) group afetr 18 days post vaccination. 

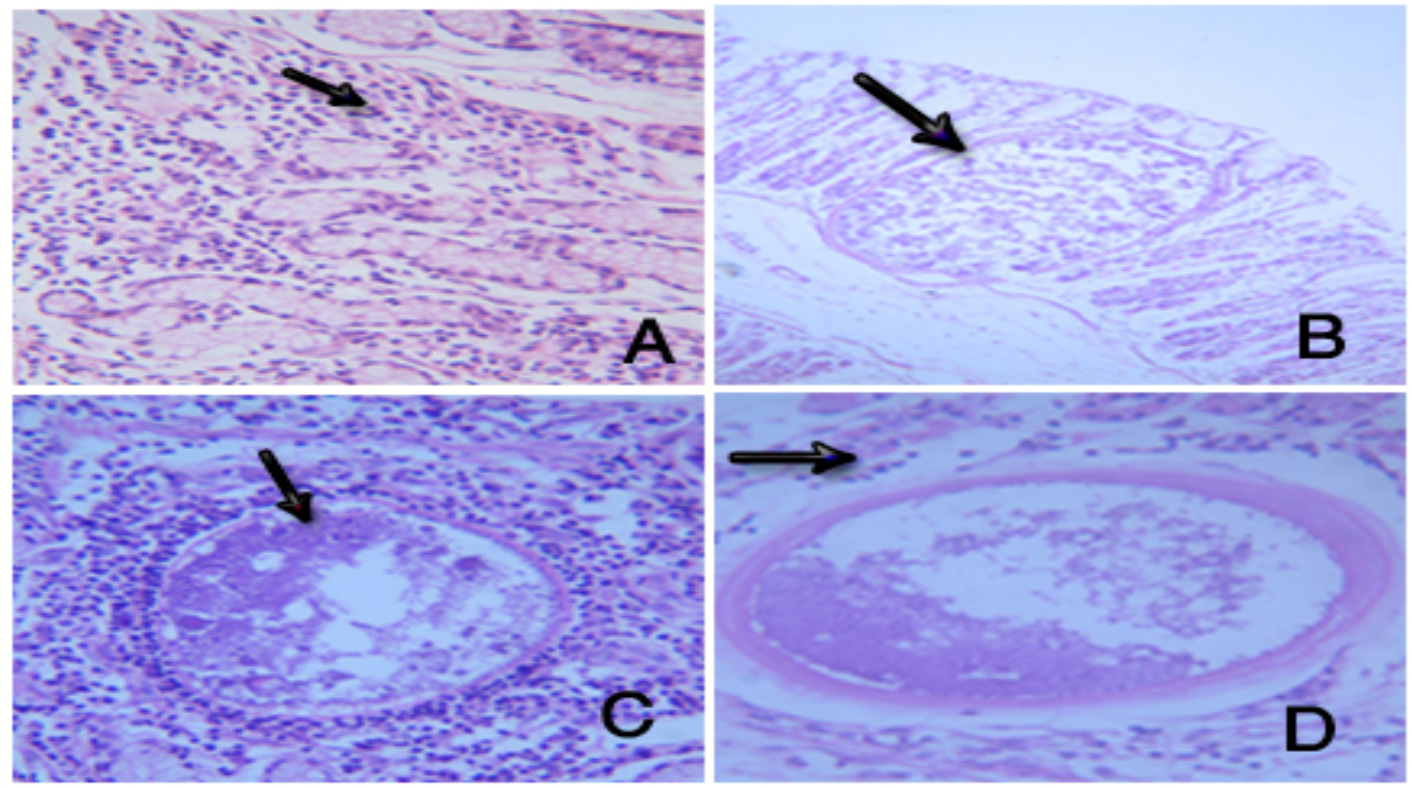

Fig. (2): A. Accumulation of inflammatory cells (mast cells, eosinophils and plasma cell) within mucosa and submucosa of abomasum. The arrow refers to eosinophiel cells (X400, H\&E). B. Degenerated larvae were detected in the omasum and were associated with mild reaction in the UV 60min group (X400, H\&E). C. Larva surrounded with marked granulomatus reaction (mast cells, eosinophils and plasma cell) in the control infected (X400, H\&E). D. Larvae within the mucosa of omasum of UV 30min, surrounded with moderate inflammatory reaction $(\mathrm{X} 400 \& \mathrm{H} \& \mathrm{E})$.

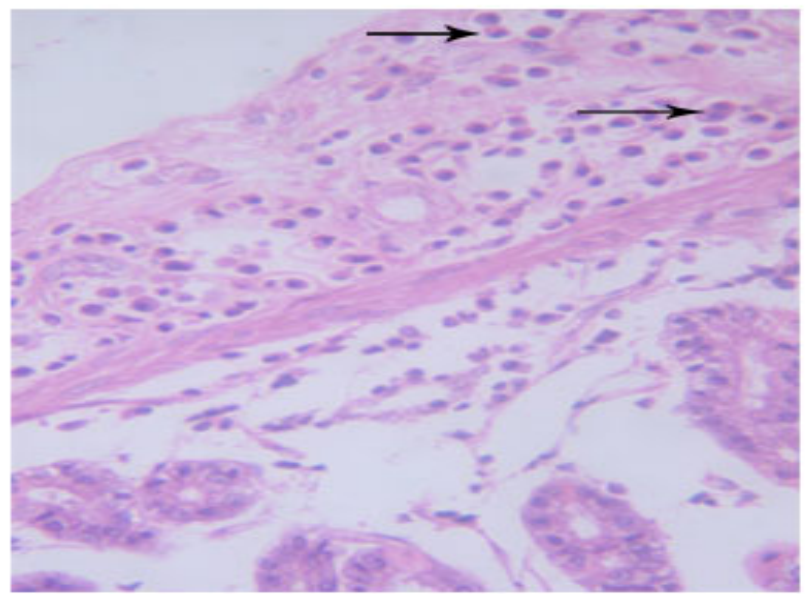

(A)

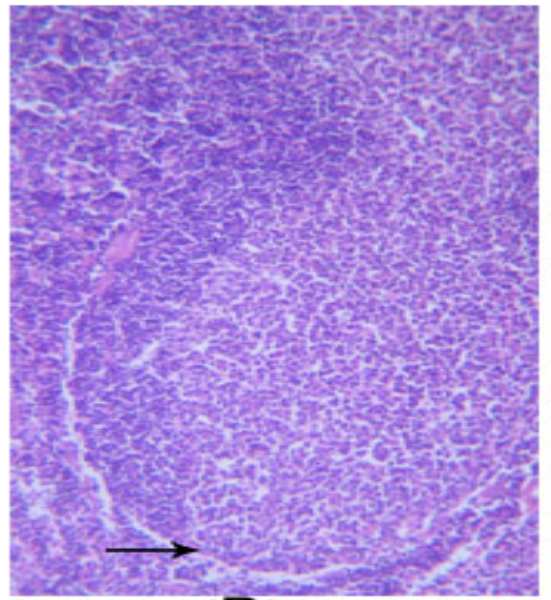

(B)

Fig 3. A. Marked granulomatus reaction with large number of plasma cells and eosinophiels were detected in omasum submucosa in UV booster 60min. B. Marked hyperplasia of lymphoid follicles, medullary cords and proliferation of lymphocytes within the lymphoid follicles of abomasal L.nds were detected with esinophilic infiltration in all groups except the control negative one.

So exposure of $H$. contortus L3 for one hour to Ultraviolet rays is sufficient for attenuation. On the other hand, few deformed eggs of large size $90-100 \mu \mathrm{m}$ in length and $45-60 \mu \mathrm{m}$ in width, with unclear segmentation (homogenous). In addition, normal eggs appeared only in UV30min group on 18 day post immunization and before challange. This may be means the exposure of $H$. contortus L3 for a half hour to Ultraviolet rays is insufficient for attenuation depending on the base of Jasmer and Mccuire (1996).

The egg production in the groups; control infected, UV $30 \mathrm{~min}$ and UV $60 \mathrm{~min}$ increased gradually till reaching the peak at 26 d.p.i. and remained stable till 36 d.p.i, then began to decline gradually. In 60 min UV booster group, 
the eggs began to appear at 18d.p.i and the curve of egg production remained stable with minor variations. These findings were like that of Jacobs et al., (1995) who showed that the fecal egg count of the sheep in the control group reached the peak on Day 26, while the highest count in the antigen group reached its peak only on Day 28. The FEC of both the control and Ag groups dropped rapidly to similar low levels by Day 32. While Dom'inguez-Tora no et al., (2000) recorded that, the peak of epg was at 30 (d.p.i).

The vaccine effects are noticed mainly on the worm fecundity by the reduction of epg. The reduction of mean epg was $93.7 \%$ inUV $60 \mathrm{~min}$ booster. This is extremely significant with the control infected group at $\mathrm{p} \leq 0.0001$. This finding was supported by Jarrett et al., (1961) who showed that $H$. contortus 10000 larvae would be required per dose (20000 per animal assuming a two-dose vaccination schedule). Furthermore, Smith and Christie (1978) who showed that two doses of Co60 irradiated $H$. contortus protected sheep against a challenge infection of 10,000 normal larvae. In addition to Smith and Angus (1980) recorded that; sheep over 7 months of age can be successfully immunized against $H$. contortus using irradiated larvae. Abbott \& Holmes (1990) vaccinated lambs with two doses of irradiated larvae, and it was equally successful in inducing a strong resistance to the challenge infection. Besides, irradiated larvae could be used to reduce the egg production of aged animals (Bain, 1999).

Concerning the efficacy of the single dose of $\mathrm{UV}$, there was no reduction in the mean of epg of 60min UV. But, UV 30min group showed mean epg higher than the control infected and this may be due to eggs of the vaccine in addition to that of challenge. This result augmented by Benitez-Usher et al., (1977) who revealed that, an irradiated $H$. contortus vaccine could not protect the most susceptible stock (lambs under 1 year old) in Haemonchus endemic areas. Besides, Smith and Christie (1979) showed that it had not been feasible to use the irradiated larvae as commercial vaccines due to failure to protect vulnerable young lambs. On the contrary, Winter et al., (2000) used a single irradiation dose which was more effective than two and three doses in the protection against parasites.

The reduction of the mean worm burden was $38.8 \%$ in UV $60 \mathrm{~min}$ booster. This result supported by Ross et al., (1979) who found that irradiated larval treatment in seven-month-old lambs reduced the worm burdens by $40 \%$ compared to controls. Moreover, Winter et al., (2000) recorded that $30 \%$ reduction in the worm burden of Suffolk lambs were given by 2 doses of 20000 gamma-irradiated infective larvae (L3) of the nematode Nematodirus battus at weekly intervals. While Menon and Bhopale (1985) found that, $99.0 \%$ and $95.0 \%$ worm reduction against the challenge doses of 100 and 1000 normal larvae respectively by using UV irradiated Ancylostoma ceylanicum. This variation may due to the nature of the parasite migration and habitat and the used host.

Regarding the establishment rate, UV $60 \mathrm{~min}$ booster gave lower rate in comparison to the other groups. Also the relative fertility was significantly reduced to $0.51 \mathrm{inUV} 60 \mathrm{~min}$ booster group. Vis versa to the other groups. This may be attributed to the developed protection by the two doses irradiated larvae.

The abomasal lymph nodes showed marked hyperplasia of lymphoid follicles and medullary cords, proliferation of lymphocytes within the lymphoid follicles. These findings come in accordance with Pérez et al., (2001) and Lacroux et al., (2006).

The tissue reaction against invading larvae were varied among the groups, in UV 30min group observation of cut larvae within the mucosa of omasum, surrounded by moderate inflammatory reaction. Although there is massive infiltration of eosinophiel within sub mucosa, the surrounding tissue reaction around larvae was moderate. In UV 60min group the animal slaughtered on 30 day post immunization and before challenge reveled that, degenerated larvae were detected in the omasum and were associated with mild reaction, the reaction were mild due to the larva were attenuated so accompanied with a weak immune reaction. The tissue reaction against larvae as which described by Pérez et al., (2001).

The plasma cells were predominant in UV $60 \mathrm{~min}$ booster group. These findings come in agreement with Scott et al., (1998) who showed that, fundic mucosal tissues are thicker due to 
mucous cell hyperplasia and marked accumulation of inflammatory cells such as lymphocytes and eosinophils, which sometimes result in nodule development.

The present results of ELISA showed that high levels of antibodies against $H$. contortus in UV 60min booster group were correlated to the resistant status of these animals. These findings stated by Dom'inguez-Tora no et al., (2000), who showed that high levels of antibodies against $H$. contortus in the immunized lambs were correlated to the resistant status of these animals.

The conclusion of this work, UV 60min booster gave a promising results in which it reduced the egg count by $93 \%$ and worm burden reduction by $34 \%$, low establishment rate $(20 \%)$ and relative fertility $(0.51)$. Also PCV values and leucocytic differential count were of the normal values (control uninfected animals).

\section{Acknowledgment}

The authors are appreciated to thank PhD Walaa Mohamed Sayed for helping us in this work.

\section{References}

Abbott, E. M. and Holmes, P. H. (1990): Influence of dietary protein on the immune responsiveness of sheep to Haemonchus contortus. Res in Vet Sci, 48 (1): 103-107.

Allam, G. and Aboel Hadid, S. M. (2009): The protective capacity of UV-exposed Clinostomum complanatum metacercariae against challenge infections in Ardeola ibis ibis. J of Helminthol, 83 (4): 361-367.

Bain, R. K. (1999): Irradiated vaccines for helminth control in livestock. Int J of Parasitol, 29: 185-191.

Carleton, M. A. (1967) : Car let on histological Technique, 4th Edn. Oxford Univ Press, New York.

Charles, T. P. and Baker, N. F. (1988): Seasonal prevalence of GINs of beef calves grazed on irrigated pasture in the lower Sacramento valley of California. Anim $\mathrm{J} 1$ of Vet Res, 49: 566-571.

Chiejina, S. N. (2001): The epidemiology of helminth infections of domesticated animals in tropics with emphasis on Fascioliasis and Parasetic Gastroenterits. Sci publishers Inc Enfield, : 41-87.

Coffin, D. L. (1995): Manual of Veterinary and Clinical Pathology. $3^{\text {rd }}$ Ed, Comst Pub Ass Inc Ithaca, New York. 115-157.

Domínguez-Toraño, I. A.; Cuquerella, M.; GómezMuñoz, M.; Mendez, S.; Fernández-Pérez, F. J. and Alunda, J. M. (2000): Vaccination of Manchego lambs against Haemonchus contortus with a somatic fraction (p26/23) of adult parasites. Parasite Immunol, 22 (3): 131-138.

Eckert, J. (1960): Die diagnose de MagenDarmstrongyliden beffales des schafes durch differenzierung der ferilebenden dritten larven. (The diagnosis of gastrointestinal strongylosis in sheep bydifferentiation of the free-living third- stage larvae.) Zentrablatt Fur Vet Med, 94: 612-629.

Gómez-Muñoz, M.T.; Cuquerella, M.; de la Fuente, C.; Gómez-Iglesias, L. A. and Alunda, J. M. (1998): Infection-induced protection against Haemonchus contortus in merino and manchego sheep. Relationship to serum antibody response. Zentralbl Veterinarmed B. 45(8):449459.

Jacobs, H. J.; Ashman, K. and Meeusen, E. (1995): Humoral and cellular responses following local immunization with a surface antigen of the gastrointestinal parasite Haemonchus contortus. Vet Immunol and Pathol, 48: 323-332.

Herlich, H. and Tromba, F. G. (1980): Effect of Ultraviolet Radiation on Some Gastrointestinal Nematode Parasites of Cattle. The J of Parasitol, 66, 4: 692-694.

Jarrett, W.; Jennings, F. W.; McIntyre, W.; Mulligan, W. and Sharp, N. (1961): Studies on immunity to Haernonchus contortus infection of sheep double vaccination of sheep with irradiated larvae. Am J of Vet Res, 20: 186-188.

Jasmer, D. P and McGuire, T. C. (1996): Antigens with application toward immune control of blood-feeding parasitic nematodes. Br Vet J, 152 (3): 251-268.

Jian, X.; Jun-Min, Y.; Hai-Chou, X.; Hui-Qing, Q.; HaiNan, R.; Hotez, P.; Bin, Z.; and Shu-Hua, X. (2006): Protective immunity elicited by ultraviolet-irradiated thirdstage infective hookworm (Necator americanus and Ancylostoma caninum) larvae in mice and hamsters. Southeast As J of Trol Med and Public Health, 37(5): 88595.

Lacroux, C.; Nguyen, T. H.; Andreoletti, O.; Prevot, F.; Grisez, C.; Bergeaud, J. P.; Gruner, L.; Brunel, J. C.; Francois, D.; Dorchies, P. and Jacquiet, P. (2006): Haemonchus contortus (Nematoda:Trichostrongylidae) infection in lambs elicitsanunequivocal Th2immuneresponse. Vet Res, 37: 607-622.

Menon, S. and Bhopale, M. K. (1985): Efficacy of UVirradiated larval vaccine of Ancylostoma ceylanicum (Looss, 1911) in golden hamsters (Mesocricetus auratus). J of Helminthol, 59 (4): 287-93.

Pérez, J.; Garcia, P. M.; Hernandez, S.; MartinezMoreno, A.; Martin de las Mulas, J. and Camara, S. (2001): Pathological and immunohistochemical study of the abomasum and abomasal lymph nodes in goats experimentally infected with Haemonch contort Vet Res, 32 (5): 463-473.

Ross, J. G.; Duncan, J. L. \& Halliday, W. G. (1979): Investigation of Haemonchus contortus infections in sheep. Comparison of irradiated larvae and transfer factor treatment. Vet Res Sci, 27 (2): 258-259.

Ruppel, A.; Shi, Y. E \& Moloney, N. A. (1990): Schistosoma mansoni and S. japonicum: comparison of levels of ultraviolet irradiation for vaccination of mice with cercariae. Parasitol, 101: 23-26.

Scott, I.; Hodgkinson, S. M.; Khalaf, S.; Lawton, D. E.; Collett, M. G.; Reynolds, G. W.; Pomroy, W. E. and Simpson, H. V. (1998): Infection of sheep with adult and larval Ostertagia circumcincta: abomasal morphology. International Journal of Parasitol, 28: 1383-1392.

Shi, Y. E.; Jiang, C. F.; Han, J. J.; Li, Y. L. and Ruppel, A. (1993): Schistosoma japonicum using ultravioletattenuated cercariae. Parasitol, 106: 459-462. 
Smith WD, Christie MG (1978) Haemonchus contortus: Local and serum antibodies in sheep immunized with irradiated larvae. Int J Parasitol, 8 (3): 219-223.

Smith, W. D. and Angus, K. W. (1980) : Haemonchus contortus: attempts to immunize lambs with irradiated larvae. Res in Vet Sci, 29: 45--50.

Smith, W. D. (1999): Prospects for vaccines of helminth parasites of grazing ruminants. Int J of Parasitol, 29: 17-24.

Soulsby, E. J. L. (1982): Helminths, arthropods, and protozoa of domesticated animals. $7^{\text {th }}$ Ed. Lea and Febiger, Philadelphia.

Tian, F.; Lin, D.; Wu, J.; Gao, Y.; Zhang, D.; Ji, M. and Wu, G. (2010): Immune events associated with high level protection against Schistosoma japonicum infection in pigs immunized with UV - attenuated cercariae. PLoS One 15, 5(10): e13408.

Winter, M. D.; Wright, C. and Lee, D.L. (2000): Vaccination of young lambs against infection with Nematodirus battus using gamma irradiated larvae. Intl $\mathbf{J}$ of Parasitol, 30 (11): 1173-1176.

Wolstenholme, A.; Fairweather, I.; Prichard, R. and Himmelsjerna A. (1992): Distribution and impact of helminth diseases of live stock in developing countries. FAO animal production and health, paper 96.

Urquhart, G. M.; James, A.; Duncan, J. and Jennings.F. (1996): Veterinary Parasitology. Blackwell Science Ltd. 